\title{
Conceptualizing, and Re-conceptualizing, Mixed Race Identity Development Theories and Canada's Multicultural Framework in Historical Context
}

Samantha Fischer

"Racism is like a fleet-footed bedbug that runs for cover under a sweet-smelling duvet stuffed with politeness and tolerance for multiculturalism" (Hill, 2001, p. 155).

\section{Scope of the topic, and paper organization}

This paper will examine the most prominent theories of identity development of mixed race people in Canada from the late 1800 s to the present day in the emergent multicultural context. It will examine the theories and contexts related to all mixed race people rather than focusing on a specific group.

This paper will commence with a discussion of the relevance of the topic, and an overview of multiculturalism policies in Canada. In the second part of the paper, the history of concepts relating to mixed race identity development in Canada will be analyzed in historical context and, when possible, related to the Multiculturalism Policy. In the third section of this paper, the current theories of mixed race identity development and multiculturalism will be addressed. Finally, the need to reconceptualize race and/or mixed race identity, and current proposals for reconceptualization will be outlined. When selecting this topic, it was assumed that identity development theories would need to be adapted to suit multiculturalism; however, it was found that the current theories addressing mixed race individuals were comprehensive, and enough empirical and theoretical evidence existed to suggest that they meet the needs of mixed race people. Thus, to address the incongruence between mixed race identity development models and multiculturalism, the focus will be placed on the latter, but a few ideas that are in accord with existing theories on Mixed Race Identity development and the empirical research to address the discrepancies will be suggested. Then, a theory of reconceptualization will be argued as the most appropriate, and the implications for research, the challenges/disadvantages, and the remaining challenges will be addressed.

This paper will be somewhat limited in its ability to discuss identity theories in an exclusively Canadian context, and it cannot accurately reflect the unique situation of the Metis peoples of Canada, or other multi-racial First Nations Peoples. This is not because this topic is unimportant. However, given the remarkably unique socio-cultural position of the First Nations Peoples in Canada, while some of the content of this paper may apply to multi-racial First Nations Peoples, it is beyond the scope of this paper to explore in a manner that would be both appropriate and comprehensive (this remains a critical direction for future work). Although the body of work on Mixed Race identity development in a Canadian context is growing, most of the research on this subject has largely been done in the United States (Taylor, 2008). When possible, exclusively 
Canadian sources are used, but they are supplemented with American sources interpreted for a Canadian context. Furthermore, due to space constraints, not every development model could be included; however, the most commonly cited, influential and representative ones have been added.

\section{Relevance of the topic}

The mixed race population in Canada is growing rapidly (Nuttgens, 2010). Between 2001 and 2006, the Mixed Race population grew from 1.2 to 1.5\% (a 25\% growth in 5 years) (Thompson, 2012). Over 340,000 children, as of the 2006 census, are growing up in Mixed Race families, and there are around 289,400 Mixed Race and common-law couples (Proudfood, 2010). This topic is relevant because this population is rapidly growing, and little work has been done on how Mixed Race individuals develop their identity in the existing framework of multiculturalism. As current multiculturalism policies are generally incongruent with the identity development models/identities of Mixed Race people, it is critical to question the adaptation of the multiculturalism policy in Canada to suit the needs of Mixed Race people, and to develop methods for Mixed Race people to live within the existing framework without compromising identities.

\section{Definition of multiculturalism as a socio-cultural theory under which to examine mixed-race identity formation}

The Multiculturalism Policy was inaugurated in Canada in 1971; it aimed to merge ethnic and national identities without compromising either (Mahtani, 2002). In its most basic form, Mahtaini (2002) defines the policy as "an adjective to refer to the multiplicity of the world's cultures and the co-existence of these cultures within particular nations" (p. 68). While initially intended to increase tolerance between groups, it is now used as a mechanism, effective or not, to engage with cultural diversity. The Multiculturalism Policy holds the four following principles:

1. to assist all Canadian cultural groups that had demonstrated a desire and effort to continue to develop a capacity to grow and contribute to Canada, and a clear need for assistance; 2. to assist members of all cultural groups to overcome cultural barriers to full participation in Canadian society; 3 . to promote creative encounters and interchange among all Canadian cultural groups in the interest of national unity; 4. to continue assistance to immigrants to acquire at least one of Canada's official languages in order to become full participants in Canadian society" (Mahtani, 2002, p. 70; The Government of Canada, 1985).

In Canada, it is both policy and law. However, the Multiculturalism Policy has created a "Hyphen Nation;" after its creation, identities such as Black-Canadian, ChineseCanadian, and Jamaican-Canadian emerged (Mahtani, 2002). The "Hyphen," or the space between the two ethnicities/races/cultures, was created in accordance with the Multiculturalism Policy to acknowledge the right of every Canadian to identify with, and to celebrate, their cultural and ethnic heritage, but to also identify with Canadian nationality (Mahtani, 2002). 


\section{The Relationship of Culture and Race}

As this paper will examine the relationships between multiculturalism and racial identity, the appropriateness of this exploration must be explored. "Culture" and "Race" are neither synonymous nor static in meaning. Cultural differences in behavior cannot be ascribed to race, and cultural traits are not "racial" traits. Despite the fact that the Multiculturalism Policy features the word "culture" rather than "race," it is still appropriate to discuss this policy in terms of its implications on racial - rather than cultural - identity (as this paper will do); this policy emerged - at least partly - in response to the influx of immigrants to Canada from non-White countries in the $1960 \mathrm{~s}$ and 1970s, and the emergent racial tensions in an increasingly racially diverse society. Therefore, as this policy was partly implemented as a means to resolve and manage racial tensions, despite being labeled a "cultural" policy, it is appropriate to explore how it affects racial identity of people in Canada. Thus, unless otherwise stated, in this paper, the word "group" applies to racial, rather than cultural groups.

\section{The Beginnings of Multiculuralism Policy: Mixed Race as a Problem}

While racial mixing, in both global and national history, is not a new phenomenon, the negative perception of Mixed Race people in Canada is as old as the nation itself; it was not until the mid-190os that tolerance grew (Rockquemore, Brunsma, \& Delgado, 2009). Moreover, from the 1800 s to the 1950 os, race was viewed as a biological concept, and defined by Census Canada as "a subgroup of the human species related by ties of physical kinship... on the basis of biological traits, such as the shape of the head, stature, colour of skin, etc" (Thompson, 2012, p. 1410). Additionally, race was classified using the one-drop rule; if an individual had any non-white heritage, he or she was not white. The label of "not white" had negative consequences, and this included one's right to enter the country, or even one's right to grow up with his or her family. Multiculturalism, at this point, would likely not have been imaginable.

\section{The Problem Approach, and the Marginal Man}

It was in this highly racist context that the "problem approach" emerged. The foundational belief to it is being Mixed Race, in itself, is problematic. The end goal of identity development was to minimize the problems brought on by membership to multiple racial groups with different social statuses (Rockquemore et al., 2009). Park (1928) affirmed that being Mixed Race is, in itself, problematic in a racist, and often racially divided, society; this social position would, according to him, result in an unavoidably negative identity development outcome of being affected by rejection, isolation and stigma.

Stonequiest (1937) expanded on the concepts developed by Park (1928), and created the Marginal Man Theory. He argues that Mixed Race people, despite the difficulties associated with their mere existence, realized the internal conflicts between partial membership to (usually) both subordinate and dominant groups (Stonequiest, 1937). The Mixed Race person, "The Marginal Man," went through three predictable 
stages of the lifecycle to reconcile the internal strife caused by both subordinate and dominant group membership/multi-group membership (Stonequiest, 1937). These steps are as follows: (a) introduction (in which the individual experiences both cultures of his/her parents), between the label given to him or her by society, and his or her own self-perceptions, (b) crisis (where the individual is shocked by society's lack of recognition of the pluralistic nature of his/her heritage, and has negative experiences where he or she realizes that the ability to exist as a bicultural/racial person, in the context of society, will be impossible), and c) adjustment (where one realizes he or she needs to identify with one group, and usually aligns with the culture of the dominant group) (Stonequiest, 1937).

These theories encompass the dominant ideology of this time, and it was not until the 1950 s that changes began to emerge in how Mixed Race people were viewed, and thus believed to develop.

\section{The Equivalent Approach, Inspiration from the Civil Rights Movement, and Growing Tolerance: Socio-political context of the 1960s}

In 1951, Canada took a large step towards what would eventually be the Multiculturalism Policy, changed the use of the word "race" to "ethnicity" on the census, and defined it as "the cultural group, sometimes erroneously called "racial" group, from which the person is descended" (Thompson, 2012, p. 1414). The One Drop rule was gone, and race was transitioning into a social, rather than biological construct; the social permission to identify with one's "cultural" group, rather than being labeled by the government as belonging in a group, indicated a growing understanding for the social concept of race. This showed a growing tolerance for Mixed Race people, and it was planting the seeds for Canada's multiculturalism policies. However, People of Colour, who were activists in the Civil Rights movement in the United States, and researchers observing the occurrences in Canada, assumed that mixed-race people (notably, in reference to Black/White mixes), regardless of their parentage, were members of the subordinate race (Rockquemore et al., 2009). Unlike in previous times, people were beginning to "pick" their race (even if the government had something else recorded on paper) (Rockquemore et al., 2009).

While it seems counter-intuitive to intentionally marginalize oneself or one's racial group, the socio-political climate, according to researchers, activists, and much of the communities of people of colour, prescribed it in this historical context (Rockquemore et al., 2009; Williams \& Williams-Morris, 2000). Instead of seeing oneself as a "lesser" person due to one's race, social dialogue in the communities of people of colour was encouraging people to see their race positively (despite the marginalization they faced, and the contradictory messages in the dominant group). Resolutely, group solidarity among subordinate groups grew (Rockquemore et al., 2009; Williams \& Williams-Morris, 2000). This was occurring more in the United States than Canada, but the messages of the Black activists in the United States during the Civil Rights Movement were making their way to Canada. There were powerful messages about self-acceptance, eliminating internal racism, personal/group empowerment, and a positive sense of group solidarity. Thus, it was believed that it was simply healthier, 
and more natural for the individual to adopt subordinate group membership (Williams \& Williams-Morris, 2000). At the very least, it was clearly better for Mixed Race individuals to be part of a group that accepted them, empowered them, and provided them with positive messages than the White groups that were marginalizing people with whom they were associated.

Additionally, with growing tolerance from the White majority, greater societal acceptance for Mixed Race couples, resulted in what Burnsama and Delgado (2009) call the "biracial baby boom" in the 1960s. The increase in Mixed Race individuals, and the change of attitudes towards them, created spaces in social, political, and academic realms for people who identified as multiracial, and more information began to be developed - from Mixed Race people themselves - about their identity development (Rockquemore et al., 2009). At this time, many immigrants from non-European countries began to arrive in Canada; this increasing diversification not only resulted in a more racially diverse society (and racial mixing in marriages and relationships), but more racially based intergroup conflicts. These conflicts, as well as the changing voting demographic in Canada, arguably were planting the seeds for the Multiculturalism Policy.

\section{Erikson's theories of development}

Many theories of development in this time held their foundations in Erikson's (1968) developmental model of ego-identity formation. In this model, the goal of adolescence is to form a stable identity that includes sense of group membership, personal sameness, and historical continuity (Erikson, 1968, as cited by Rockquemore et al., 2009). This is accomplished by the transition through a series of exploratory and experimental stages. Ego-identity formation is evident decisions, and commitments, in areas of social life ranging from religion, political orientation, and career paths (Erikson, 1968, as cited by Rockquemore et al., 2009). Racial identity formation was linked to a similar process as forming ego identity as, since race is a social construct, it demands similar commitments in social domains (Erikson, 1968, as cited by Rockquemore et al., 2009). "Committing" to a race (usually the "subordinate" race) was, thus, the dominant ideology of this time. One was expected to commit to being the oppressed or the oppressor. When one has to reconcile racial heritage of being both the "oppressed" and "oppressor," many mixed-race people identified with their "oppressed" race (in this case, meaning "not white"); this is not surprising, as it is somewhat counter-intuitive to align oneself with a majority group that partly oppresses part of one's identity. Furthermore, in the case of people who had one parent who was clearly not white, aligning oneself with the majority group who has been oppressing a non-white parent with whom one has affective ties, could result in feeling as though one has betrayed his/her family.

\section{Socio-Political Climate of the late 1960 s and 1970 s}

During the 1960s and 1970s, many non-White immigrants were entering the country, and tensions were growing between Francophones and Anglophones (Mahtani, 2002). Due to a public outcry from all stakeholders, the Canadian government changed 
how it responded to diversity (Mahtani, 2002). Thus, Canada adopted the Policy of Multiculturalism in 1971 (Mahtani, 2002). In this time of increasing tolerance, a great deal of research on Mixed Race identity development emerged (Mahtani, 2002).

\section{William Cross' Nigresence model}

One of the most cited and popular, empirically investigated models of multiracial identity development from this time is William Cross' Nigresence model (Cross, 1971, as cited by Rockquemore et al., 2009). This model addressed the identity development of Mixed Race black individuals exclusively (presumably due to the high population of black mixed-race people in North America compared to other groups), but it can be applied to other mixed individuals. In this model, the individual transforms from "Negro-to-Black" in a series of steps (Cross, 1971). The first step is the pre-encounter stage. At this time, presumably in early childhood, the individual does not acknowledge the existence of race or racism, and tends to adopt the dominant (white) culture (Cross, 1971). However, at some point, the individual attends a radicalized event, and is immersed in the subordinate (in his theory, Black) culture. At this point, the encounter stage begins. Here, the individual learns how to be Black (or, a member of one or more of his/her subordinate racial group memberships) (Cross, 1971). As one continues to develop, the internalization stage begins; the individual adopts the subordinate identity, and an image of the self as a member of this group (Cross, 1971). Then, the racial identity becomes an anchor, defense, and a foundation of the self (Cross, 1971). The final stage is commitment. This simply involves the ongoing expression of the minority identity (Cross, 1971). Racial identity was considered in this model, as in the Marginal Man and Erickson model, as linear, and with an end point that resulted in the adoption of a single racial identity (Cross, 1971). This fit the mono-racial concept of Multiculturalism.

\section{The Equivalent Approach, Growing Tolerance, and the Demand for Plurality: The Socio-political Climate of the 1980 s}

By the mid-1980s, many of the children of the "Mixed Race baby boom" of the 1960 s were reaching adulthood, and engaging in research. The research on multiracial individuals was now being done almost exclusively by multiracial individuals who, based on the radical difference in theories generated in this time compared to the theories in the previous 100 years, were likely finding existing models of identity development insufficient (Rockquemore et al., 2009). Furthermore, due to the increasing number of biracial, or multiracial individuals, an increasing demand to recognize multiracial people as a unique group emerged from individuals and activists; the need for this recognition was demanded, by activists and multi-racial people, to be reflected in the census (Rockquemore et al. 2009; Williams, 2006). In 1996, Canada let people selfidentify as multi-racial on the census, reflecting a growing tolerance for Mixed Race individuals, and also the emergent belief that one could identify with more than one race (Thompson, 2012). 


\section{The Equivalent Approach}

Instead of suggesting that individuals should adopt one racial identity, it was proposed that they should be viewed as distinct from any single racial group (Rockquemore et al., 2009). In this approach, problems still exist, but the problems were no longer regarding the racial background of the individual like in previous models, but found in the process of identity development.

\section{Root's Encouragement of Multiple Identities}

Root (1992) proposed that the Mixed Race population was not only a distinct group, but rather, Mixed Race individuals were able to develop healthily as multiracial individuals. This substantial break from the tradition of pathologizing the development of Mixed Race individuals, and suggesting that they needed to adopt one identity, was groundbreaking (Rockquemore et al., 2009). While this broke ground in terms of identity development theories, it also diverged from Canada's theories of multiculturalism; Mixed Race people no longer, under this model, could associate with one racial group, and this is because they no longer belonged to a distinct group, but to two or more. While Canada was encouraging groups to form around race to celebrate their heritage, Mixed Race people were, for the first time, beginning to be excluded from both the majority and the minority groups; unlike in the 1960s when mixed Black and White individuals were probably finding less acceptance from the black community because they were embracing their white identities, and less acceptance from the White community for identifying as a radicalized individual.

\section{Adolescent Development}

Furthermore, Gibbs (1989) and Herring (1992) discussed the challenges of identity development in mixed-race adolescents. First, these individuals were forced to integrate dual racial identities and learn how to develop positive self-concept and feelings of competence (Gibbs, 1989; Herring, 1992). Then, they had to concurrently gain the ability to synthesize earlier identifications from childhood into a stable sense of self, and into a positive racial identity. In this process, developmental problems may emerge, including, but not limited to, conflicts about their racial identity, conflicts about their social marginality and privilege (if they have a White parent), and conflicts about allegiance to one parent based on race.

\section{Potson's Biracial Identity Development Model}

Potson (1990) developed one of the most commonly cited studies on Mixed Race identity development. His Biracial Identity Development Model closely resembles Cross' (1971) Nigresenceance model, but in contrast to the Cross (1971) model, where one chooses to align one's identity with one race, the Potson (1990) model culminates with the individual adopting a multiracial identity. The stages are as follows: 1) Personal Identity (which is developed in childhood in peer/family interactions), 2) choice of group categorization (where one encounters a racial crisis, and is forced to pick one 
racial identity), 3) denial (where one feels guilt and confusion about rejecting part of one's identity), 4) appreciation (where one adopts, and learns to appreciate, his/her multiple identities), and 5) integration (where one feels whole as a result of accepting his/her multiple identities) (Potson, 1990).

\section{Current Concepts of Multiculturalism and Mixed Race Identity Development - The Ecological Approach: Present Day}

Since 1996, the Canadian Census has encouraged individuals, rather than just providing them with the option, to check more than one "race" box on the census; this indicates a continued growing acceptance of Mixed Race peoples (Thompson, 2012). In the present, the most common approach to racial identity development in Mixed Race people is the ecological approach (Thompson, 2012). Instead of focusing on developmental end goals, the theories generated under this approach focus on the context of identity development; this reflects some of the emergent themes in developmental psychology. Furthermore, there is a large body of empirical evidence supporting the ecological approach in our current societal context, resulting in high measures in self-esteem, self-acceptance, feelings of belonging, personal/group empowerment, and self-confidence for those who adopt it (Nakagawa, 2005). All theories under this approach hold the following assumptions:

(a) mixed-race people construct different racial identities based on various contextually specific logics, (b) there are no predictable stages of identity development because the process is not linear and there is no single optimal endpoint, and (c) privileging any one type of racial identity over another (i.e., multiracial over single-race identity) only replicates the essentialist flaws of previous models with a different outcome (Rockquemore et al., 2009, pp. 19).

\section{Rejection of Racial Identity}

Under the Ecological Framework, individuals are given the opportunity to refuse racial identity, and to identify as simply "human" (Daniel, 2001). However, as previously stated, one of the elements of the multiculturalism policy is "to promote creative encounters and interchange among all Canadian cultural groups in the interest of national unity" (Mahtani, 2002, pp. 70). The policy, which encourages group identification, is operationalized in many parts of Canadian society; K-12 students are, for example, often asked to bring in something that represents their "group" in celebrations of diversity. However, when one refuses to identify with a single racial or cultural group, and to identify as "human," he or she is, under this policy, removing him or herself from a group, and thus removing him or herself from group-based discourse/encounters in Canadian society. Furthermore, as this group-based discourse, exchange and interchange is supposed to promote national unity, refusing to identify as a member of a group - with differences from other groups - could be viewed as a threat to national unity. 


\section{Identity and Place}

In Mahtani's (2002) qualitative study between geographic location and racial identity in multiracial Canadian women, she found that the women often changed their racial identity depending on the place they are in. Her findings indicated that:

in some places, [the women] might be seen as black, in others they might be seen as white. But, the only stable reading of their identity is that these readings are always changing, and very hard to predict. The ways we are raced, gendered and classed alters daily (Mahtani, 2002, p. 44).

Unlike the stones in a mosaic, racial identity is not fixed "in stone," but constantly shifting. Many of the Mixed Race women in Mahtani's (2002) study also said that they are constantly being "given" identity by other people, both from subordinate and dominant groups, and the identity which they are given depends on a myriad of factors including, but not limited to, the time of year (and, thus, how much the sun has darkened one's skin), the length of one's hair, the presence or absence of makeup, and even type of one's clothes. This fluid identity contradicts and challenges Canada's assumptions of different, fixed, but harmonic racial groups; this may, in turn, render the multiculturalism policy insufficient for multiracial Canadians.

\section{Identity Fluidity}

The racial identity of Mixed Race people has been shown to change over time, and there is currently no empirical evidence to suggest that there is a developmental endpoint of racial development in Mixed Race individuals (Gaston, 2003; Mahtani, 2002; Wallace, 2001).

\section{Mixed Race as a Race}

It may be appropriate for some people, in order to reconcile the internal divide that many multi-racial people experience, to identify exclusively as Mixed Race, and for "Mixed Race" to become a race itself (Williams, 1999). In this case, all Mixed Race people could cease to fragment their identity, and to integrate their identities linguistically, socially, and cognitively. Furthermore, it is possible based on shared experiences of fragmentation, sitting on racial boundaries, and exclusion from society that Mixed Race people experience, they may have more in common with other mixed people (regardless of the mix) than with monoracial groups.

\section{Re-conceptualizing Mixed-race identity in Canada}

\section{Need for re-conceptualization}

Canada's multicultural ideology is the lens through which Canadians view cultural diversity, and develop, articulate, and understand their own racial identities and place in Canadian society (Taylor, 2008). However, under the policy of 
multiculturalism, little room is made for Mixed Race people to allow people to publicly identify with more than one race, or as raceless; it is expected that people adopt the "hyphenated" race (Taylor, 2008). Despite the well-meaning nature of this policy, it arguably singles out people according to ethnicity and race, and makes some more "Canadian" than others. It holds the underlying assumption that Canada is a European nation with French and English roots. Europeans are "Canadians," and visible minorities are the people who have "culture" in comparison to the "standard" White majority (Bannarji, 2000; Li, 1999; Taylor, 2008). This effectively otherizes any people without "Canadian" heritage (Taylor, 2008). These "cultures" are singled out for food, and clothing, and those "with culture" are expected by "Canadians" to be a more or less homogeneous group with the same aspirations, goals, and traditions (James, 2003). Once again, although culture and race are not synonymous, the clear radicalized origins and undertones of the multiculturalism policy are clear through this otherization of non-White members of Canadian societies; if this policy were simply about culture, all Canadians - not just Canadians of Colour - would be expected to adopt a hyphenated identity to "celebrate" their heritage and group themselves. Unlike Canadians of Colour, White Canadians are seemingly excluded from the requirement to hyphenate their identities, despite the fact that they have diverse cultural practices.

In a society where the dominant ideology is to identify with one group, or to force the hyphenation of identity, a problem arises because, as discussed, Mixed Race people often find hyphenation - or adopting a single race - insufficient to capture their identity (Nakagawa, 2005). This makes people, notably those with less common mixes, struggle to find a racial group to which they belong in a society where identifying with - and socializing with - a racial group is considered to be a critical aspect to one's identity (Nakagawa, 2005). However, while those who identify as mixed, or those who identify with a hyphenated race have difficulty finding the Canadian-prescribed "racial/cultural group" either in theory or in reality, many have trouble with acceptance as a "member" of a mono-racial group. Many Mixed Race people face rejection or otherization from these groups for being inauthentic or not "-insert ethnicity here- enough" to fully "belong" (Nakagawa, 2005). This sometimes results in the individual compromising his or her racial identity to "belong," but it can also result in the mono-racial group members - from all of the racial groups to which a Mixed Race person identifies with reject the individual as a group member for not being "insert ethnicity here" enough. Under the current societal framework of multiculturalism, this leaves the individual between the prescribed racial boundaries, and with rare options for belonging (Nakagawa, 2005). The lack of "belonging" has the obvious result of feelings of distress, otherization, and isolation, but also, according to Thakur (1994), it can result in internalized racism (Nakagawa, 2005). For Mixed Race people to avoid negative situations such as these, multiculturalism needs to be reconceptualized.

Furthermore, multiculturalism creates a "burden of hyphenation where one is seen as not solely 'Canadian' but 'Canadian and fill-in-your-ethnic-background”' (Mahtani, 2002, p. 19). There are largely negative consequences of this for Mixed Race people; although it has been argued both theoretically and empirically that Mixed Race people in modern Canadian society experience the most desirable identity formation trajectory when allowed to identify their race freely and fluidly. This forces multiracial 
individuals - in order to be visible, and to navigate the social structures of society - to adopt identities that make sense within this "hyphen-nation" ideology (Mahtani, 2002; Taylor, 2008). In addition, it "de-Canadianizes" those with non-European heritage (who can, but are not forced to, adopt a hyphenated identity to reflect their cultural and/or racial background). Mixed-race people are not permitted to be simply mixed, but instead are forced to adopt the hyphenated identity that results from multicultural ideology (Mahtani, 2002; Taylor, 2008). The "Hyphen Nation" ideology overlooks the complexity of Mixed Race identity (Mahtani, 2002; Taylor, 2008). Mixed Race people do not exist as "Ethnicity 1 - Ethnicity 2/3/4/5/etc.," and claim that their identity is none of the ethnicities in the Canadian hyphenated identity, but actually found only in the hyphen itself. Defining one's self by the ethnicities alone is insufficient for most mix race people to capture their complex identity - as they are not one thing or the other but a distinct mixture of both (Nakagawa, 2005).

Moreover, multiculturalism demands one to form a cultural association based on race. Thus, one is forced to "adopt" a race, and as minorities are still subject to racism in Canada. Minorities are therefore only forced to embrace their "race," and the marginalization that comes with it from the existing social systems and structures for non-White individuals (Mahtani, 2002; Taylor, 2008). According to Hill (2001), a prominent mixed-race Canadian writer, "Racism is like a fleet-footed bedbug that runs for cover under a sweet-smelling duvet stuffed with politeness and tolerance for multiculturalism" (p. 155); this reflects much of the current academic work regarding racism in Canada.

Furthermore, although Canada claims to be a diverse society, there is a long history of racism towards non-European individuals in the country; this includes the limitation of the settlements of non-European Canadians and the treatment of the First Nations Peoples in residential schools (the last of which closed in the 1980s), and the Internment of people of Japanese Origin in Canada. Despite efforts to be a "progressive" and "accepting" society, this history still plays a role in subordinating nonEuropean people (Taylor, 2008). The Multiculturalism Policy promotes otherization, and is viewed by some to be a palatable extension of Canada's historically racist policies.

Multiculturalism supposedly places its focus on cultural rather than racial diversity, and thereby claims to support the choice of the individual to associate or identify with cultural practices without discrimination (Elliot \& Fleras, 1996; Taylor, 2008). Even with this in consideration, in a qualitative study done by Mahtani (2002), it was found that Mixed Race women viewed this policy as having no positive effect on their lives (despite the amount of money spent by the government on it), fragmenting society by dividing people into racial groups (in which Mixed Race people often do not fit), and even being "cheesy." These findings support the claim that this policy is not only ineffective for mixed-race people, but focuses (despite claims to the contrary) on both the culture and race of Canadians. If every tile in the mosaic is a distinct ethnic/cultural group, there seems to be no place for the Mixed Race individual but in the grout, and no room in a hyphenated identity but in the hyphen.

Furthermore, many mixed-race university students in Canada, despite having 
been well educated on the subjects of race and equality, feel both excluded and unacknowledged in schools and cultural organizations (Taylor, 2008). Although there is a great deal of societal activity surrounding the promotion of diversity and the celebration of heritage, almost none of these events recognize the unique place of the large population of Mixed Race people in their organization or delivery (Taylor, 2008). Again, this is a way in which "multiculturalism" works for mono-racial people, but leaves no space for Mixed Race people.

In addition to conceptually excluding multi-racial people in the discussion of Multiculturalism in Canada, despite the size of the population, very little attention is given to Mixed Race individuals by the Canadian Government. Taylor (2008) believes this is because Mixed Race people pose an irreconcilable challenge to the idea of multiculturalism (for which Canada prides itself), and that it is, therefore, more simple to ignore the unique issues faced by this group than to change the policies or concepts in multiculturalism that are "inherent" to the national identity of many mono-racial people. It is argued by Mahtini (2002) that "the more that mixed-race identities challenge the norms of what is understood as 'Canadian,' the more mixed-race people will be positioned as doubly different, doubly strange, and doubly foreign” (p. 84). Moreover, According to Hill (2001) "Canadians are quick to point out what we of Mixed Race are not-we are not white, and we are not black-but they don't tell us what we are. ... This is the quintessential Canada: the True North, Proud, and Vague" (p. 228). The solutions to the conflict between multiculturalism and Mixed Race identity are just as vague as the lack of their concrete identification of Mixed Race people described by Hill (2001). Mixed Race people have the opportunity to have an identity that does not conflict with social ideology. The existent social ideology may need to be changed or modified. The Government of Canada has no apparent obligation to do this, but as the population of Mixed Race people grows, the government may be put under increasing political pressure to meet the needs of multiracial people in the same way that it meets the needs of mono-racial, White Canadians.

To sum up the problems faced by Mixed Race Canadians under the Multiculturalism Policy, Nakagawa (2001) cites a Mixed Race person saying the following, comprehensive, statement about the multiculturalism and Mixed Race identity: "Multiculturalism was never really designed to imagine me."

\section{Current proposals of re-conceptualization}

Despite the inadequacies, and writings about these inadequacies of multiculturalism as it exists today to facilitate - or even not hinder - the identity development of Mixed Race people, there are virtually no viable solutions proposed. Some unfeasible, imaginative, solutions proposed by researchers include waiting for everyone to become blind to race, or dissolving all nation states (Mahtani, 2002). Without a clear vision from the multiracial community, or even the existence of a multiracial community (even the researchers appear to be fragmented, and variant in their beliefs) to create an alternative to multiculturalism, it is slightly challenging to propose reconceptualization. However, there may be some small governmental changes, and changes to how Canadians see identity, that would facilitate a constructive 
reconceptualization.

\section{Change Multiculturalism Policies: Multi-racial Multiculturalism}

According to Thompson (2012), in the 1996 census, as a result of the ability for people to select more than one box describing their race, Canada shifted away from multiculturalism, and into a new paradigm of multiracial multiculturalism. Multiracial multiculturalism occurred

[when mixed-race] identities were acknowledged as part of - rather than problematic within - diverse societies and could be recognized as a positive attribute of the multicultural nation. More specifically, this normative change was spurred by a growing awareness of the multiracial population, which stemmed partly from demographic trends and increasingly unsettled perceptions about discrete racial categories, as well as a transnational norm in census-taking that gave credence to the notion of self-identification. These factors possess both ideational and institutional elements and together enabled mixed-race to be employed and promoted, at times strategically, as a corollary of multicultural discourse. (Thompson, 2012, p.1409)

While this concept seems ideal, and to resolve a lot of the negative components of multiculturalism, the existing research on the experiences of multiracial people with multiculturalism indicate that no such change has taken place. However, if this was added to the existing legislation on multiculturalism, promoted by the government, and adopted by society (to the extent that the multiculturalism policy itself was), it could result in racial self-identification being acceptable in all levels of society (rather than just on the census), and could result in heritage celebrations (from which Mixed Race people are often, at best, partially included in), education about self-identification rights, and research to ensure the needs of Mixed Race people were being met. This supports some of the theories that have been proposed and investigated in the ecological framework (Nakagawa, 2005).

\section{Mixed Race as a "Race"}

Another solution could come from the multi-racial community; the government may not need to re-conceptualize multiculturalism, but multi-racial people may need to re-conceptualize - on a large scale - how they define their racial identity. As it is critical in Canadian multi-cultural society to belong to a group through self-identification, multi-racial people could define themselves as a unique race - rather than a mix of races - and thereby form the socially prescribed racial group required by multiculturalism. There are a number of additional reasons why Mixed Race individuals may wish to consider adopting "Mixed Race" as their race. According to an empirical study conducted in Canada and the United States, having one's multiracial identity validated by others and society, in contrast to being invalidated or contextually developed, is associated with higher levels of identity integration and self-concept clarity (Lou, Lalonde, \& Wilson, 2011). Therefore, if "Mixed" were to be considered a race itself, and people were no longer forced to adopt two identities, or to have their identities 
constantly questioned, the fragmentation caused by forcing people to align with one of their ethnicities would likely greatly diminish; they could create the group that multiculturalism prescribes for all members of society. Then, Mixed Race people would fit in the concept of multiculturalism. By re-conceptualizing Mixed Race identity, and adopting multi-racial multiculturalism, some of the existing incongruences between being multi-racial, and existing in a multi-cultural society may be solved.

\section{Re-appropriating "Canadian," and removing the hyphen}

The label "Canadian" (without the hyphen) is often reserved for individuals with European heritage. However, Mahtani (2002) suggests that, if the multiculturalism policy remains unchanged in principle, mixed-race people could re-appropriate the term "Canadian." If Mixed Race people, as well as other groups, identify solely as Canadian, there is then a place for Mixed Race people in the policy, and within the social groups in Canada (as one would be in a "group" that the multiculturalism policy resuscitates). Another reason for this is that the hyphen (inherent to current Canadian social thought on diversity) creates space between people, and space between their identities. By removing the hyphen in social discourse, one can defragment his or her own identity, and, in turn, communities could, perhaps, be less fragmented by the racial divides that Mahtani (2002) believes the hyphen creates.

\section{Summary}

It is recommended that Canada adopt and implement an official policy of multiracial multiculturalism, that Mixed Race people be encouraged to define themselves as mono-racial "Mixed Race" people, or as "Canadian" without the hyphen. However, based on the ecological model, it is critical that the fluidity of identity of Mixed Race people is maintained, as it is inherent to being Mixed Race. Thus, while these viewpoints should be encouraged, perhaps in the education system, they should not be presented as the only options for identity development, and racial alignment.

\section{Implications of re-conceptualization for research, and challenges and disadvantages of Reconceptualization}

If we are to re-conceptualize how we view the interaction between multiculturalism and Mixed Race, research will need to be done to determine exactly what the Mixed Race community wants; there is very little discussion of this. Moreover, in examining what Mixed Race people want, it may be found that people with different mixes - based on their cultural backgrounds - desire different re-conceptualizations.

By grouping everyone together as "Mixed Race" or "Canadian," there would be no way to analyze which group differences actually exist. Next, very few or scattered, established communities of Mixed Race people exist; finding research participants may prove challenging. Finally, as the needs of our society evolve with social/historical change, research done now may become irrelevant very quickly. Even over the past 30 years, there have been drastic shifts in how Mixed Race people themselves view identity, and all of these theories are linked to specific historical conditions. It would be very 
challenging to monitor the needs, and implement the changes with sufficient time.

However, many mixed-race individuals are hesitant to homogenize the experience of mixed-race peoples by adopting a singular mixed-race identity (Mahtani, 2004); it is likely that most Indian-Swedish people, for instance, have had very different life experiences, and thus possibly values, than Chinese-South Africans. Therefore, saying what "Mixed Race people want," and grouping all Mixed Race people together, poses obvious challenges. Yet, extensive research has not been done on this subject, so these concerns are currently hypothetical.

\section{Remaining questions and challenges}

The question remains as to how Mixed Race people in Canada can either reform, or replace, the existing policy on multiculturalism, and if Mixed Race people wish to be viewed as a homogeneous group with similar developmental trajectories. If they do not wish to be viewed as a homogenous group, then the question is left as to if there is an alternative to the hyphen nation. With fragmented communities, viewpoints, and apparent lack of interest from the federal government, these questions and challenges will be hard, but not impossible, to address. But, it appears that Mixed Race people themselves may need to organize their own communities to define and affect the desired change. 


\section{References}

Bannerji, H. (2000). The Dark Side of the Nation: Essays on Multiculturalism, Nationalism and Gender. Toronto: Canadian Scholars' Press.

Berry, J. W. (1997). Immigration, acculturation, and adaptation. Applied Psychology, 46(1), 5-34. doi: 10.1111/j.1464-0597.1997.tb01087.x

Canadian Association of College and University Student Services. (1999). Policy and Procedures Manual, revised. Retrieved from http://www.cacuss.ca/files/cacuss/policymanual.pdf.

Chakraborty, M., James, C. \& Shadd, A. (2002). Talking about Identity: Encounters in Race, Ethnicity, and Language. Herizons 16 (2), pp.53.

Cross, W. E. (1971). The Negro-to-black conversion experience: Toward a psychology of black liberation. Black World, 2O, 13 - 27.

Daniel, G. R. (2001). More than black? Multiracial identity and the new racial order. Philadelphia.

Elliott, J. L., and Fleras, A. (1996). Unequal Relations: An Introduction to Race and Ethnic Dynamics in Canada. (2nd ed.) Upper Saddle River, N.J.: Prentice Hall.

Erikson, E. (1968). Identity: Youth and crisis. New York: Norton.

Gatson, S. (2003). On being amorphous: Autoethnography, genealogy, and a multiracial identity. Qualitative Inquiry, 9, 20 - 48.

Gibbs, J. T. (1989). “Biracial adolescents.” In J. T. Gibbs \& L. N. Huang (Eds.), Children of color: Psychological interventions with culturally diverse youth (pp. 332 350). New York: Jossey-Bass.

Herring, R. (1992). Biracial children: An increasing concern for elementary and middle school counselors. Elementary School Guidance and Counseling 27, 123 - 131.

Hill, L. (2001). Black Berry Sweet Juice: On Being Black and White in Canada. Toronto: Harper-Collins Canada.

James, C. E. (2003). Seeing Ourselves: Exploring Race, Ethnicity and Culture. Toronto: Thompson Publishing.

Khan, S., and Pavlich, D. (2000) Academic Freedom and the Inclusive University. Vancouver: UBC Press. 
Latchford, C. (2004). Diaspora? How does a bi-racial women of francophone heritage, adopted and raised in Toronto locate herself in diaspora?. Canadian Woman Studies, 23(2), 164.

Li, P. (1999). “The Multiculturalism Debate.” In P. S. Li (ed.), Race and Ethnic Relations in Canada. (2nd ed.) New York: Oxford University Press.

Lou, E., Lalonde, R. N., \& Wilson, C. (2011). Examining a multidimensional framework of racial identity across different biracial groups. Asian American Journal of Psychology, 2(2), 79-90. doi:10.1037/a0023658

Mahtani, M. K. (2002). The geographies of identity [being a person of 'mixed race']. Canadian Issues, 44.

Martin, J., \& Gillespie, A. (2010). A neo-meadian approach to human agency: Relating the social and the psychological in the ontogenesis of perspective-coordinating persons. Integrative Psychological and Behavioral Science, 44(3), 252-272. doi:10.1007/s12124-010-9126-7

Osborne, K. (2000). Public schooling and citizenship education in Canada. Canadian Ethnic Studies, 32(1), 8.

Park, R. (1928). Human migration and the marginal man. American Journal of Sociology, 33, $881-893$.

Poston, C. W. (1990). The biracial identity development model: A needed addition. Journal of Counseling and Development, 69, $152-155$.

Proudfoot,S. (2010). Mixed-race marriage increasingly common; Statistics Canada says five per cent of children have parents from different cultures. The Vancouver Sun, pp. B.1.

Razack, S. (1999). Looking White People in the Eye: Gender, Race, and Culture in the Courtrooms and Classrooms. Toronto: University of Toronto Press, 1999.

Rockquemore, K. A., Brunsma, D. L., \& Delgado, D. J. (2009). Racing to theory or retheorizing race? Understanding the struggle to build a multiracial identity theory. Journal of Social Issues, 65(1), 13-34.

Root, M. P. (Ed.). (1992). Racially mixed people in America. Newbury Park, CA: Sage.

Simon Nuttgens. (2010). Biracial identity theory and research juxtaposed with narrative accounts of a biracial individual. Child \& Adolescent Social Work Journal, 27(5), 355-364. doi:10.1007/s10560-010-0209-6 
Spencer, R. (2006). Challenging multiracial identity. Boulder, CO. Lynne Rienner Publishers.

Stonequist, E. V. (1937). The marginal man: A study in personality and culture conflict. New York: Russell \& Russell.

Taylor, L. (2008). "Black, White, Beige, Other? Memories of Growing Up Different.” In C. E. James (ed.), Experiencing Difference. Halifax: Fernwood.

Thakur, S. (1994). Domino: Filming Stories of Interracial People. In C. Camper (ed.), Miscegenation Blues: Voices of Mixed Race Women. Toronto: Sister Vision Press.

The Government of Canada. (1985). Canadian Multiculturalism Act (R.S.C., 1985, c. 24 (4th Supp.). Justice of Laws Website. Retrieved from http://lawslois.justice.gc.ca/eng/acts/C-18.7/page-1.html\#h-1.

Thompson, D. (2012). Making (mixed-)race: Census politics and the emergence of multiracial multiculturalism in the United States, Great Britain and Canada. Ethnic and Racial Studies, 35(8), 1409-18. doi:10.1080/01419870.2011.556194

Wallace, K. (2001). Relative/outsider: The art and politics of identity among mixedheritage students. Westport, CT: Ablex.

Warren, J., \& Twine, F. (1997). White Americans, the new minority?: Non-blacks and the ever-expanding boundaries of whiteness. Journal of Black Studies, 28, 200 218.

Williams, C. B. (1999). Claiming a biracial identity: Resisting social constructions of race and culture. Journal of Counseling \& Development, 77(1), 32-35.

Williams, D. R., \& Williams-Morris, R. (2000). Racism and mental health: The African American experience. Ethnicity and Health, 5(3-4), 243- 268.

Williams, K. (2006). Mark one or more: Civil rights in the multiracial era. Ann Arbor: University of Michigan Press.

Yancey, G. (2003). Who is white?: Latinos, Asians, and the new black/nonblack divide. Boulder, CO: Lynne Rienner Press. 